\title{
Natural and engineered bacterial outer membrane vesicles
}

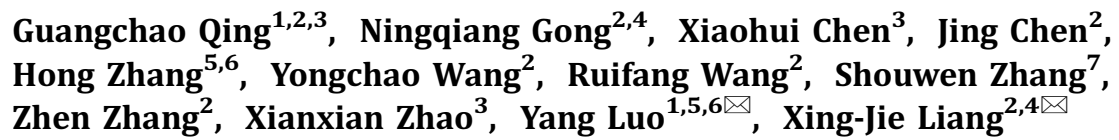

1 Department of Materials and Energy, Southwest University, Chongqing 400715, China

${ }^{2}$ Chinese Academy of Sciences (CAS) Key Laboratory for Biomedical Effects of Nanomaterials and Nanosafety, CAS Center for Excellence in Nanoscience, National Center for Nanoscience and Technology of China, Beijing 100190, China

${ }^{3}$ Department of Clinical Laboratory Medicine, Southwest Hospital, Army Medical University, Chongqing 400038, China

${ }^{4}$ University of Chinese Academy of Sciences, Beijing 100049, China

${ }^{5}$ Key Laboratory for Biorheological Science and Technology of Ministry of Education, State and Local Joint Engineering Laboratory for Vascular Implants, College of Bioengineering, Chongqing University, Chongqing 400044, China

${ }^{6}$ Nuclear Medicine and Molecular Imaging Key Laboratory of Sichuan Province, Department of Nuclear Medicine, the Affiliated Hospital, Southwest Medical University, Luzhou 646000, Sichuan, China

${ }^{7}$ West Essence Clinic, Beijing Institute of Functional Neurosurgery\&Xuanwu Hospital, Capital Medical University, Beijing 100053, China

Received: 28 March 2019 / Accepted: 15 May 2019 / Published online: 1 October 2019

Abstract

Bacterial outer membrane vesicle (OMV) is a kind of spherical lipid bilayer nanostructure naturally secreted by bacteria, which has diverse functions such as intracellular and extracellular communication, horizontal gene transfer, transfer of contents to host cells, and eliciting an immune response in host cells. In this review, several methods including ultracentrifugation and precipitation for isolating OMVs were summarized. The latest progresses of OMVs in biomedical fields, especially in vaccine development, cancer treatment, infection control, and bioimaging and detection were also summarized in this review. We highlighted the importance of genetic engineering for the safe and effective application and in facilitating the rapid development of OMVs. Finally, we discussed the bottleneck problems about OMVs in preparation and application at present and put forward our own suggestions about them. Some perspectives of OMVs in biomedical field were also provided.

Keywords Bacterial outer membrane vesicles (OMVs), Biogenesis, Preparation, Application

\section{INTRODUCTION}

Living organisms tend to secrete factors such as proteins, molecules, polysaccharides, and other substances directly or indirectly to sustain their physiological activities (Brown et al. 2015; Schwechheimer and Kuehn

$\triangle$ Correspondence: luoy@cqu.edu.cn (Y. Luo), liangxj@nanoctr.cn (X.-J. Liang)
2015). Besides direct excrete of some cellular factors, many factors are secreted through the extracellular vesicles (EVs), indicating that the vesicles may play an important role in the living process. Different from exosomes, EVs, or membrane structures obtained from cell lysis, bacterial outer membrane vesicle (OMV) is naturally derived from the cell envelope of Gramnegative and Gram-positive bacteria (Brown et al. 2015; 
Shen et al. 2012; Turnbull et al. 2016). As shown in Fig. 1, OMV is a spherical nanostructure with a diameter of $20-250 \mathrm{~nm}$ and contains the phospholipid bilayers that are incorporated with various bacterial proteins, lipopolysaccharides (LPS), and lumens carrying periplasmic constituents (Kaparakis-Liaskos and Ferrero 2015; Kim et al. 2015a, b). The discovery of the OMV under various growth conditions and other natural environments in all investigated bacteria indicates that the secretion of OMV seems to be an evolutionary conserved process (Orench-Rivera and Kuehn 2016). OMV has a fundamental role in microbial physiology and pathogenesis, including intracellular and extracellular communication, horizontal gene transfer, transfer of contents to host cells, and eliciting an immune response in host cells (Kuehn 2012; Kulkarni and Jagannadham 2014). OMV obtained from Escherichia coli (E. coli) was first reported in the 1960s, but the existent OMV produced by Gram-positive bacteria (Bacillus subtilis and Bacillus cereus) was first mentioned in literature in 1990, which may be caused by the different structure of cell wall between Gram-negative and Gram-positive bacteria (Bishop and Work 1965; Dorward and Garon 1990).

The biogenesis of OMV is a complex process (Kulkarni and Jagannadham 2014; Ruiz et al. 2006; Schwechheimer and Kuehn 2015). Here, we briefly introduce four major models that had been proposed to elucidate the formation mechanisms of OMV (Fig. 1). Loss or relocation of covalent linkages, via lipoproteins or other ways, exists between the outer membrane and the underlying

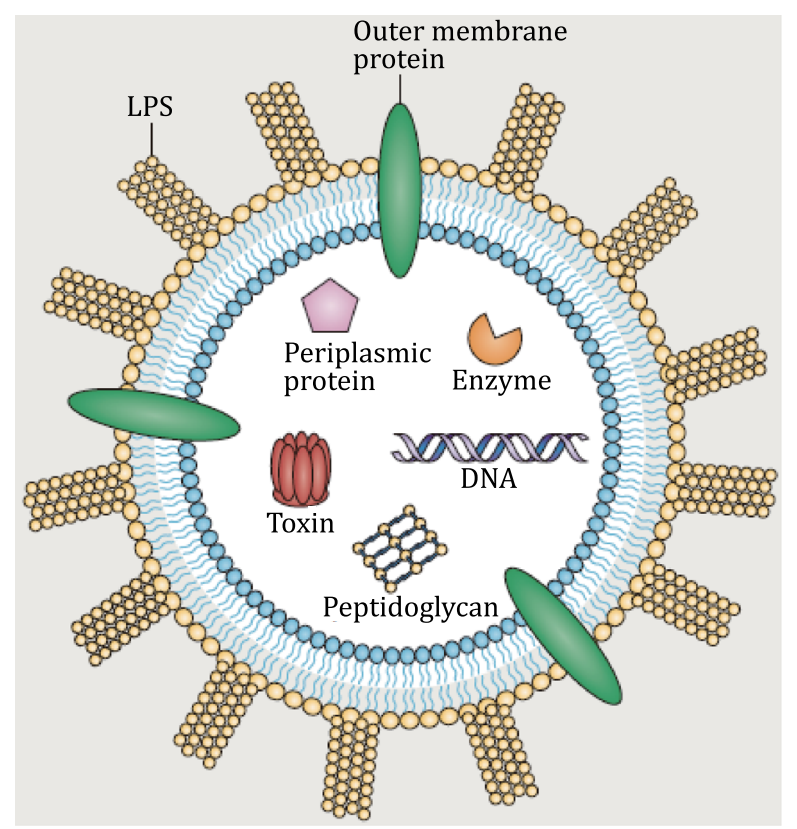

Fig. 1 Structure and contents of Gram-negative bacterial OMV (Kaparakis-Liaskos and Ferrero 2015) peptidoglycan layer. When the defect occurs, faster growth rate of the outer membrane than the underlying cell wall allows the outer membrane to protrude and finally generate OMV. This is the principle of the first model (Kulkarni and Jagannadham 2014; Kulp and Kuehn 2010). The establishment of the second model is based on the interaction between the outer membrane and turgor pressure, which is generated from the accumulation of peptidoglycan fragments or misfolded proteins in the periplasmic space and cause the outer membrane to bulge and finally to pinch off (Haurat et al. 2015). It is hypothesized that increasing the amount of membrane curvature-inducing molecules, such as B-band LPS and quinolone Pseudomonas aeruginosa ( $P$. aeruginosa) quinolone signal (PQS) of Pseudomonas aeruginosa, can enhance anionic repulsions between LPS molecules, which will result in membrane blebbing by sequestering divalent cations (Kulp and Kuehn 2010; Schertzer and Whiteley 2012). Through a mechanism of asymmetric expansion of the outer leaflet of the outer membrane, the PQS can induce the formation of OMV. And based on this hypothesis, the third model is constructed. Although the PQS-based model is one of the best studied so far, it is limited by the fact that PQS is only produced by $P$. aeruginosa and therefore species specific. Based on the phenomenon that knockout or repression of $V a c J / Y r b$, two genes associated with phospholipid transporter, will increase OMV production in some Gram-negative bacteria, the forth model is proposed (Roier et al. 2016). In this model, phospholipid will accumulate in the outer leaflet of the outer membrane when vacJ and/or yrb genes are silenced or deleted, which then results in an asymmetric expansion of the outer leaflet and subsequently promotes an outward bulging of the outer membrane. In both leaflets, the enrichment of positive and negative curvature induced by phospholipids facilitates the budding of the outer membrane, which finally pinches off to form an OMV (Fig. 2). This model can act in concert with all other three OMV formational models proposed hereinbefore and can almost perfectly represent the mechanism of secretion of OMV by Gram-negative bacteria. However, this model cannot fully explain why the OMV contains substances, such as DNA, that are inside the bacterial inner membrane. Therefore, more sophisticated models are needed to further explain the mechanism of $\mathrm{OMV}$ formation.

Beside obtained from the natural secretion, treatment of bacteria with external stimulus such as detergent, oxidative stress, and temperature stress can also promote the production of OMV (Baumgarten et al. 2012; MacDonald and Kuehn 2013; van de Waterbeemd et al. 2013). There are some differences between naturally 


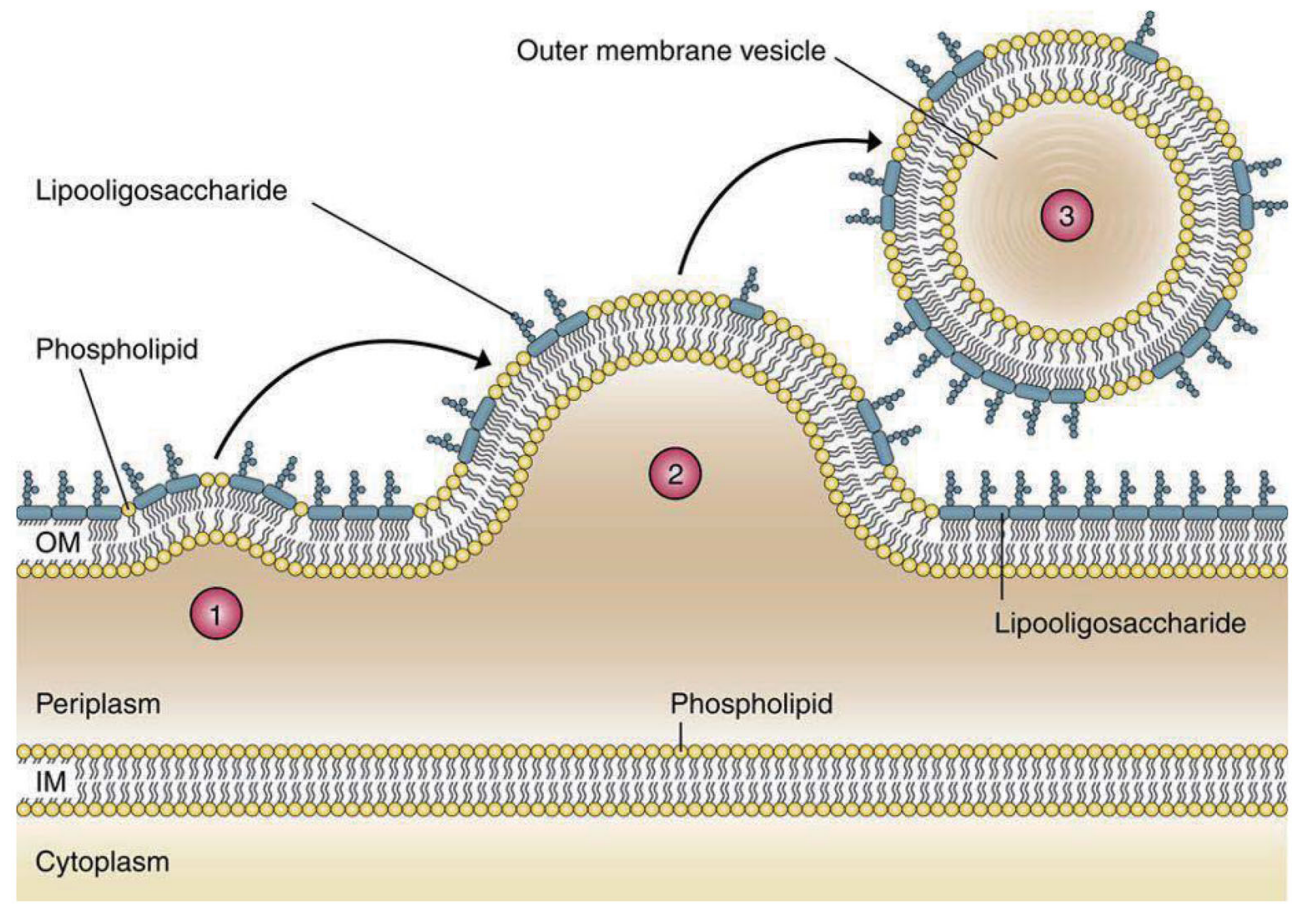

Fig. 2 A typical biogenesis of OMV of Gram-negative bacteria (Roier et al. 2016)

and artificially $\mathrm{OMV}$, and many works have shown that OMV can differ in their structure and composition generated from the subtle differences during the formation processes (Gnopo et al. 2017). According to these differences, OMV can be carefully classified into several different categories (Fig. 3). Based on the differences in the preparation process between OMVs produced naturally from native bacteria vesiculation and produced by mechanical means, Kuehn et al. divided the OMVs into native and non-native. However, in recent review by Yehou M.D. Gnopo et al. (2017) and van der Ley et al. (2015), OMVs were classified into four types including detergent OMVs (dOMVs), native OMVs (nOMVs), spontaneous OMVs (sOMVs), and engineered OMVs (gOMVs). The dOMVs lack some typical components found in a bacterial outer membrane because of the use of detergent in the productive process. However, nOMVs are produced by using sonication but not detergent. The sOMVs are produced naturally from budding of bacteria, the equivalent of Kuehn's native category (Kulp and Kuehn 2010). And the gOMVs, abbreviated as sOMVs in the original review, are extracted from genetically engineered bacteria and have been widely used in biomedical applications. A recent review summarized by Toyofuku et al. (2019) divided the bacterial membrane vesicles from Gram-negative bacteria into outerinner membrane vesicles (OIMVs), explosive outermembrane vesicles (EOMVs), and traditional OMVs according to their formation routes, structures, and compositions, which extended the scope of the bacterial membrane vesicles. In addition, the OMVs secreted from Gram-positive bacteria are termed as cytoplasmic membrane vesicles (CMVs) and considered as one independent bacterial membrane vesicle (Fig. 3).

Although the OMVs have been discovered for a long time, there are still only a few methods to prepare and purify the vesicles, and some defects still exist in the existing methods during the isolation process. This review outlines several major methods that have been successfully applied to prepare the OMVs, including ultracentrifugation and precipitation. Meanwhile, this review will demonstrate some significant progresses of OMVs, especially the genetically modified OMVs, which have made in vaccine development, tumor treatment, bacterial infection, and biological detection in recent years.

\section{METHODS FOR PREPARATION OF OMV}

OMV is a subcellular component that consists of the phospholipid bilayer, membrane protein, lipopolysaccharide, nucleic acid molecule, and other substances, and shown as a spherical nanostructure with a cavity inside. For the same bacteria, different culture conditions and growth stages will result in different components on the surface of OMV, so it is difficult to acquire the homogeneous OMVs (McCaig et al. 2013; 


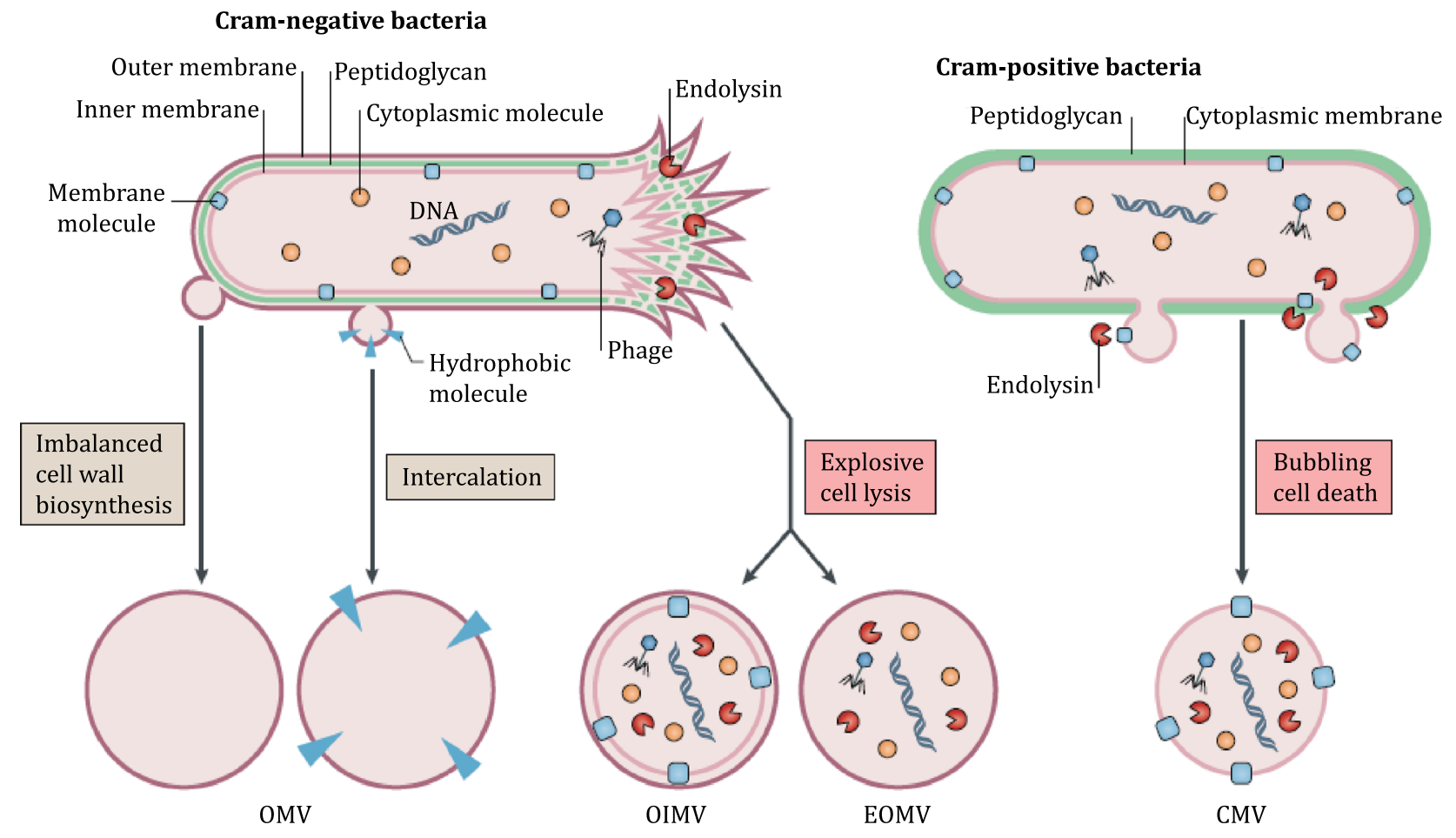

Fig. 3 Different routes lead to the formation of distinct membrane vesicle types. Gram-negative bacteria have two main routes for vesicle formation: blebbing of the outer membrane and explosive cell lysis. Endolysin also triggers 'bubbling cell death' in Gram-positive bacteria, in which it gives rise to cytoplasmic membrane vesicles (CMVs). CMVs can contain membrane and cytoplasmic components. Other peptidoglycan-damaging enzymes and treatments may have similar consequences as endolysin (Toyofuku et al. 2019)

Orench-Rivera and Kuehn 2016). We will introduce two major ways that have been successfully applied to prepare the OMVs as follows (Fig. 3).

\section{Ultracentrifugation}

In 1960s, ultracentrifugation was first used to prepare OMVs, and the first TEM images of what have been identified as OMVs from Gram-negative bacteria were reported in 1966 (Knox et al. 1966). Since then, ultracentrifugation method has gradually become the most important method for preparation of OMVs. The process of the ultracentrifugation includes the following steps. Firstly, bacteria were cultured in the suitable fluid medium for a specified time. Bacterial cells and debris distributed in the culture are removed by centrifugation and the collected supernatant is subsequent filtration through a $0.45-\mu \mathrm{m}$ pore size filter to remove residues. The cell-free filtrate is then concentrated to small volumes with a $100-k D a$ hollow filter membrane. Finally, the concentrated supernatant is pelleted by ultracentrifugation at $100,000-200,000 \mathrm{~g}$ for a certain time, and the obtained pellet is OMVs while the soluble proteins remain in the supernatant. By optimizing the cultural conditions and the centrifugal speed and time in the preparation procedure, more uniform OMVs would be prepared through this method (Fig. 4).

To further improve the purity and quality of OMVs, sequential density gradient centrifugation can be adopted after the ultracentrifugation. Samples are added into an inert gradient medium for centrifugal settlement or settlement balance, and the target products will be distributed to certain specific position in the gradient under a certain centrifugal force during the process of ultracentrifugation. Iodixanol, sucrose, dextran, and other substances that meet the requirements can be used to prepare the inert gradient medium. Postprocess about the sequential density gradient ultracentrifugation is as follows: the pellet got from the previous step is then resuspended in the prepared inert gradient medium of highest gradient concentration and ultracentrifugation at $200,000 \mathrm{~g}$ for a specific time. And the purified OMVs can be harvested from the certain layer.

Based on this method, OMVs generated from many non-genetically or genetically modified Gram-negative bacteria such as E. coli, P. aeruginosa and Salmonella typhimurium have been successfully extracted with 
A

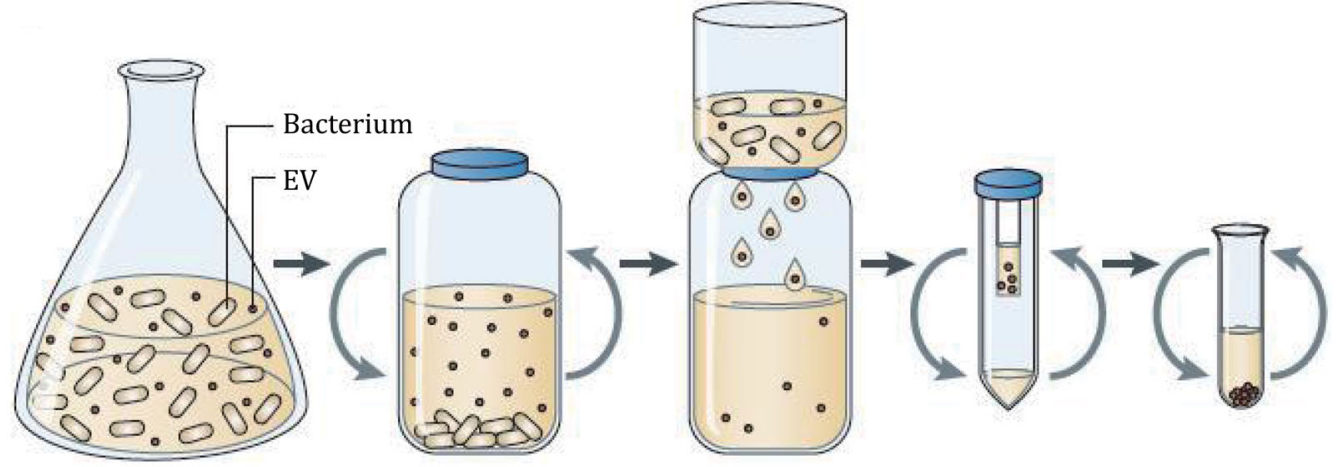

B

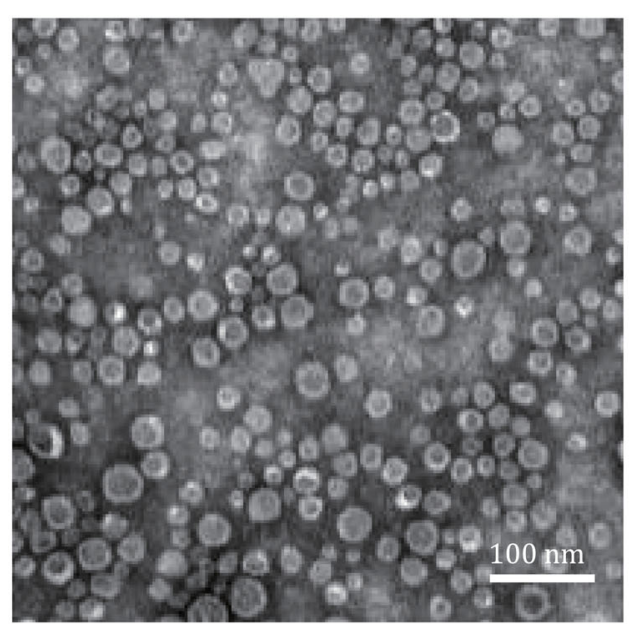

C

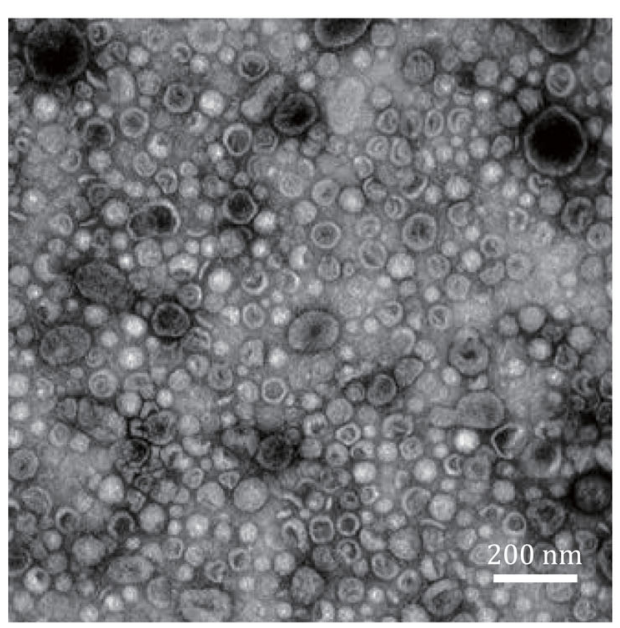

Fig. 4 Isolation of OMVs. A The general protocol for purifying OMVs derived from bacteria (Brown et al. 2015). TEM images of OMVs isolated from genetically modified E. coli (Kim et al. 2017a, b) (B) and Acinetobacter baumannii (Li et al. 2015) (C)

uniform morphology and homogeneous size (Guidi et al. 2013; Kim et al. 2017a, b; Mashburn and Whiteley 2005). OMVs from Gram-positive bacteria such as Staphylococcus aureus (S. aureus), Bacillus subtilis, and Streptococcus pneumoniae can also be isolated through this method (Lee et al. 2009; Toyofuku et al. 2017; Yuan et al. 2018). The successful application of the ultracentrifugation not only provides favorable assistance for extraction of OMVs but promotes the development and application of OMVs in many fields.

Although the ultracentrifugation method has been widely used in the preparation of OMVs, there are still some deficiencies. The complex operative procedure and the cost of a lot of time are two main problems of this method. Meanwhile, the machine of the ultracentrifugation has potential risk when operated, which challenges the operational skills and psychology of operator during the process. In addition, the machine is very expensive and difficult to popularize to every researcher in the field. This, in turn, will limit the development of the OMVs and affect the progress of the follow-up lines of research.

\section{Precipitation}

For a protein solution, the balance of surface charges and hydrogen bonds that keep the soluble stable can be destroyed when the high concentration of salt is added. And the proteins will subsequently aggregate with each other and lead the mass addition of the aggregation making isolation by centrifugation easier. This mechanism is also suitable for isolation of OMVs, indicating that precipitation can be another practical approach for extracting OMVs (Klimentova and Stulik 2015). There are two main routes to achieve the extraction of OMVs through precipitation. Adding the saturated salt solution prepared previously to the supernatant that the bacterial cells and debris have been removed. After the general centrifugation, the OMVs can be precipitated successfully. However, added large volumes of saturated salt solution to the supernatant may complicate its further processing. To avoid this problem, the homogenized solid salt like ammonium sulfate (AS) with high solubility in water and adequate ionic strength can be directly added to the supernatant. It should be noted that the solid salt should be homogenized and the 
addition procedure must be performed very slowly to control the size of the formed crystal and to avoid the formation of overconcentrated zones, respectively. Finally, the precipitated and centrifuged OMVs from both routes should be dialyzed to remove the soluble solid salt before further use (Klimentova and Stulik 2015).

Based on the precipitation, OMVs from Porphyromonas gingivalis are collected by using the AS at $40 \%$ saturation (Li et al. 1998). The saturation of the salt solution may increase after the precipitation, which was proven by Oishi et al. When OMVs are collected, the saturation of salt solution increases from $40 \%$ to $75 \%$, indicating that there are some free extracellular proteins released from bacteria that may non-specifically bind to the salt (Oishi et al. 2010). The saturation of the salt solution should be determined carefully and some corresponding inhibitor for these undesired proteases should be added into the media prior to the concentration step, which will improve the quality and maintain the stability of the surface proteins of OMV (Bauman and Kuehn 2006). In order to further improve the purity and size homogeneity of the obtained OMVs by precipitation, density gradient centrifugation as well as gel filtration (gel sieving, size exclusion chromatography) is also needed (Kataoka et al. 2014). Unlike the density gradient centrifugation, gel filtration is a technique of elution and separation based on molecular sieves of particles with porous network structures and the different molecular weights of each component in the tested samples. OMVs with the same protein molecular weight will be purified through this method while OMVs with the same buoyancy density will be collected by density gradient centrifugation.

Compared with ultracentrifugation, the key and difficult point of precipitation is to prepare salt solution with proper concentration and saturation as well as the rotation speed used to concentrate the formed crystal. The whole process is also complex, and the proteins on the OMVs will be threatened by the high concentration proteases released from bacteria when centrifugation. Moreover, the addition of protease inhibitors into the filtered culture media prior to the concentration step will increase the useless contents of the solution, which will set up a barrier for further purification of the OMVs.

Limited by the purity, quality, and homogeneity of the prepared OMVs, other methods like ultrasonication are only used within a limited kind of bacteria. Moreover, OMVs obtained through these two methods often need further purification by any of the above two methods, so it is rarely used alone of these two methods for preparation of the OMVs. In general, the separation and purification of OMVs are very complicated. Although
OMVs with stable morphology and uniform size have been able to extract by the ultracentrifugation and precipitation methods, the complexity of the operation process, a lot of time and energy consumed in separation and purification, and high cost of the methods still existed subsistent, which cannot meet the requirements from other lines of research and will seriously limit its development and application in the biomedical field. Therefore, it is very urgent to upgrade the existing techniques or develop simple and feasible methods.

\section{BIOLOGICAL APPLICATIONS OF OMV}

OMV carries many characteristics of the outer membrane of the bacteria. LPS is one of the special components on the surface of the OMV, which makes the OMVs toxic to host cells. For Gram-positive bacteria, the component that plays the same role like LPS is the lipoteichoic acid (LTA), which could only be found in the bacterial cell wall (Bitto and Kaparakis-Liaskos 2017). LPS can be found exclusively in the outer leaflet of the outer membrane of Gram-negative bacteria besides OMVs and have been introduced carefully in previous studies (Silhavy et al. 2010). Together with other features presented on parent bacterium, the OMV can act as a mini-bacterium to participate in mediating diverse physiological functions, including assisting bacterial communication with each other, increasing bacterial adaptation and survival in the hostile host environment, resisting the attack of antibiotics, and promoting delivery of virulence factors and pathogenesis (Kulkarni et al. 2014; Manning and Kuehn 2011; Schwechheimer and Kuehn 2013).

OMV may directly interact with epithelial cells or pattern-recognition receptors such as toll-like receptor (TLR) to induce or inhibit the production of cytokines and chemokines by epithelial cells to regulate inflammatory cells (Kaparakis-Liaskos and Ferrero 2015) (Fig. 5). At the same time, the interaction between OMVs and epithelial cells can also disturb the cellular mucosa, promote the transfer of OMVs and the entry of bacterial toxic factors into the submucosa, thereby promoting the interaction of OMVs with neutrophils, dendritic cells, and macrophages (Kaparakis-Liaskos and Ferrero 2015). OMV contains a large number of immune antigens with auxiliary characteristics, which can activate innate immunity and promote the occurrence of adaptive immune response (Ellis and Kuehn 2010). Thus, OMV has a potential function in vaccine delivery. Although the presence of these TLR antagonists substantiates the immuno-stimulatory effects of OMVs, they can cause uncontrolled responses like inflammation 


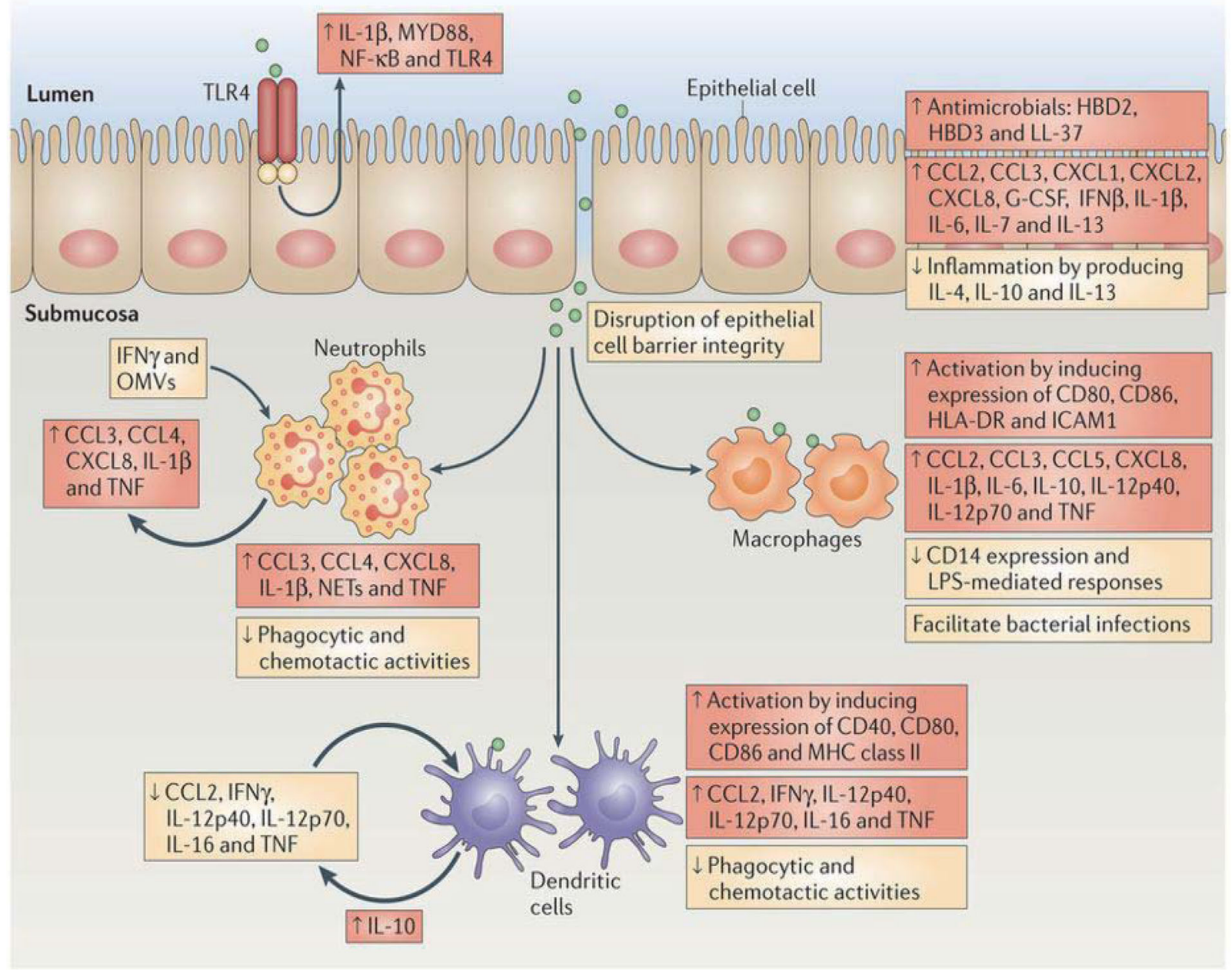

Fig. 5 Interactions of OMVs with epithelial and innate immune cells. OMVs from multiple pathogens interact with epithelial cells and innate immune cells in various ways to either facilitate (orange boxes) or limit (yellow boxes) inflammation and the recruitment of inflammatory cells to the mucosal epithelial cell surface (Kaparakis-Liaskos and Ferrero 2015)

when the OMVs are used in excess (Gnopo et al. 2017; Xue et al. 2015). For example, treatment with high levels of LPS will induce the strong protection from the immune system of the animals, which will lead to fever and septic shock (Kuipers et al. 2015). Thus, in order to prepare a safe and effective vaccine within the tolerance level of the body, the usual amount of these immune antigens on the surface of OMVs needs to be effectively managed. Safety also needs to be addressed with OMVs from these hosts to become a suitable option for other types of applications.

There are mainly two approaches to remove the endotoxins from OMVs. First approach is an artificial method that does not change the genes that code for LPS in the bacteria strain and can be applied to post-OMV (van de Waterbeemd et al. 2010). Profiting from the characteristics of structure of LPS, appropriate chemical reagents such as non-ionic detergents and chelating agents are used during the process of preparation to treat the OMVs, sequentially reduce or dissolve the LPS. Based on the genetic engineering, another elegant approach that acts on LPS-synthesis pathway in the host bacteria strain is proposed to prepare the OMVs with attenuated forms of LPS (Needham et al. 2013; Needham and Trent 2013). Although satisfied OMVs can be got through both methods, improper use of chemical reagents will cause loss of lipoproteins and other enzymatic proteins as well as the activity, which would impair the ability of OMVs to initiate cross-protective immunity. In contrast, the transformation of bacteria strain through genetic engineering not only attenuates LPS exclusive, but also maintains the ability for inducing desired pathogen-specific immune responses of OMVs, which is more suitable for non-endotoxin transformation of OMVs (Bitto and Kaparakis-Liaskos 2017; Kim et al. 2017a, b; van der Pol et al. 2015). Next, this review 
will highlight the latest advances of genetically engineered OMVs in vaccine development, infection control, cancer treatment, and bioimaging and detection (Table 1).

\section{Genetically engineered OMVs for vaccine development}

With the continuous aggravation of bacterial drug resistance and the failure of traditional vaccines in serious side effects including inflammation, toxicity, and poor stimulation of cell-mediated or mucosal immunity, it is urgent to develop new vaccines for preventing and controlling bacterial pathogens (Pathirana and Kaparakis-Liaskos 2016). Profiting from their immunogenic properties, OMVs from Gram-negative and Grampositive bacteria have been investigated as antigen adjuvant or vaccine candidate for many years (Bjune et al. 1991; Petousis-Harris et al. 2017). In fact, the OMV-based vaccine like Bexsero, a meningococcal group B vaccine, is approved by the U.S. Food and Drug Administration (FDA) for preventing invasive disease caused by Neisseria meningitidis serogroup B in individuals 10 through 25 years of age (Vernikos and Medini 2014).

Bacterial OMVs obtained from some bacteria can increase the antibody levels and result in strong cellmediated and humoral immune responses in mice, which will reduce the bacterial burden and prolong the survival of mice (Huang et al. 2014; Yuan et al. 2018). Based on the cavity structure, OMVs can also be used as antigen delivery device for increasing the antigen presentation and immune response. The polysaccharide produced by Bacteroides fragilis can be loaded in the corresponding OMVs, and the system can prevent experimental colitis by promoting regulatory $\mathrm{T}$ cell responses and suppressing proinflammatory cytokine production (Shen et al. 2012). OMVs derived from Bacillus anthracis contain one or more biologically active toxins that can induce the immune system of mice to produce a robust IgM response, which would protect mice from challenge of Bacillus anthracis again (Rivera et al. 2010). However, these OMVs possess the selfadjuvanting properties naturally, and employing them as the devices for transporting the target adjuvants or antigens may cause serious side effects like septic shock for human body in some cases, which will reduce the therapeutic effect for bacterial infections (Chin et al. 2013). For these reasons, some modifications are required for improving the biosafety of OMVs. The genetic engineering technique is one of the alternative approaches.

OMV can be used as a safe vaccine delivery device or antigen adjuvant after minimizing amount or passivating activity of the components like LPS or LTA (van de Waterbeemd et al. 2010). Compared to traditional method like chemical modification based on the structure of LPS or LTA, the biosafety of OMV will be improved after the rational genetic manipulation, which will further increase the therapeutic potential of OMV (Choi et al. 2015). Some studies have shown that OMVs from genetically engineered bacteria such as E. coli, Neisseria meningitidis and S. aureus show low toxicity and can effectively induce antibody-mediated immunity or innate immune response (Fantappie et al. 2014; Zariri et al. 2016).

Heterologous oligosaccharide and polysaccharide antigens can be displayed on the OMVs by remodeling the carbohydrate portion of LPS (Valentine et al. 2016). The geOMVs, meaning glycoengineered outer membrane vesicles, generated from non-pathogenic $E$. coli that had been modified by genetic engineering demonstrate the target glycan of the pathogen on their surface and can be used as vaccines to against Streptococcus pneumoniae and Campylobacter jejuni (Price et al. 2016). Another example is the glycosylated OMVs, glycOMVs, which can be obtained from several different pathogenic bacteria by engineered modification (Chen et al. 2016). The glycOMVs can play a role of vaccine and delivery

Table 1 Biomedical applications of OMVs and their superiority and deficiency

\begin{tabular}{|c|c|c|c|}
\hline Application & Superiority & Deficiency & Example \\
\hline $\begin{array}{l}\text { Vaccine } \\
\text { development }\end{array}$ & Easily customization; & Complex preparation process; & $\begin{array}{l}\text { Petousis-Harris et al. (2017), } \\
\text { Thoma et al. }(2018)\end{array}$ \\
\hline $\begin{array}{l}\text { Infection } \\
\text { control }\end{array}$ & $\begin{array}{l}\text { Safe delivery device for } \\
\text { vaccine and proteins; }\end{array}$ & response and subsequent inflammation & $\begin{array}{l}\text { Huang et al. (2016), Gao et al. } \\
\text { (2015), Yuan et al. } 2018 .\end{array}$ \\
\hline $\begin{array}{l}\text { Cancer } \\
\text { treatment }\end{array}$ & $\begin{array}{l}\text { Stimulate the body to } \\
\text { generate immune }\end{array}$ & & $\begin{array}{l}\text { Kim et al. }(2017 \mathrm{a}, \mathrm{b}), \text { Gujrati } \\
\text { et al. }(2014)\end{array}$ \\
\hline $\begin{array}{l}\text { Bioimaging } \\
\text { and } \\
\text { detection }\end{array}$ & $\begin{array}{l}\text { protection; } \\
\text { Protect the protein and } \\
\text { soluble materials within it }\end{array}$ & & $\begin{array}{l}\text { Gujrati et al. (2014), Chen et al. } \\
\text { (2017) }\end{array}$ \\
\hline
\end{tabular}


platform at the same time and are able to induce the antibody response and T-cell response, protecting the mice from lethal challenge. Similar vaccines that prevent infections caused by other pathogens can be obtained quickly through the same way.

The target objects like antigens and proteins can be anchored on the outer membrane of bacteria through genetic engineering, resulting in the formation of OMVs with specific protein, which can effectively elicit specific immune responses (Thoma et al. 2018). By genetically fusing to the anchor protein cytolysin A (ClyA), OMVs demonstrating several heterologous proteins were constructed from E. coli and Salmonella enterica (Chen et al. 2010). Based on the ClyA, the green fluorescence protein (GFP) can also be expressed on OMVs, which can act as vaccine and fluorescent booster at the same time. The influenza matrix protein 2 (M2e) can also be integrated on the surface of OMV isolated from E. coli through the same way, and the prepared M2e OMV vaccine can induce high IgG titers in mice and provide a strong protection against lethal PR8, H1N1, and H3N2 influenza challenge in mice (Watkins et al. 2017).

Like adjuvants or vaccines, OMVs can induce immune protection that can protect human body from related bacterial infections. OMVs with specific function can be obtained by genetic engineering and the associated vaccines have been approved for the treatment of meningitis in clinic, which will accelerate the advance of the OMVs in turn.

\section{Genetically engineered OMVs for infection control}

Previous studies have shown that OMVs can effectively aggregate at the infected site, stimulate the body to produce a strong and last protective immune response and humoral immunity in infected mice (KaparakisLiaskos and Ferrero 2015; Jang et al. 2015). This is an antigen-specific IgG and/or IgA antibody-responsive process (Fantappie et al. 2014; Romeu et al. 2014). The antigens will be presented to $\mathrm{CD} 4+\mathrm{T}$ cells through antigen-presenting cells (APCs), and then stimulate the body to generate the antigen-specific B-cell responses that will wipe out the antigens and establish the immunoprotection (Apostolico Jde et al. 2016; Sharpe et al. 2011). During the infection with pathogens such as Shigella flexneri, E. coli, S. Typhimurium, H. pylori, and V. cholerae, the secreted OMVs can induce the protective immune responses that can relieve the burden from infection and defend the mice against sepsis or death (Chatterjee and Chaudhuri 2013; Kim et al. 2013; Vanaja et al. 2016). At the same time, interferon- $\gamma($ IFN- $\gamma$ ) and interleukin-17 (IL-17) can be produced through immune system under the stimulation of OMVs, which will then induce the Th1- and Th17-based cell response to achieve the effective killing of homologous bacteria in vivo. Another study has shown that with the immunity of OMVs, the polymorphonuclear leukocytes from body show effective destruction against Neisseria meningitidis, suggesting that neutrophils may contribute to OMV-mediated protection against this pathogen (Kim et al. 2013).

Assisted by recombinant genetic technology, an outer membrane protein of A. baumannii, Omp22, was displayed on E. coli DH5 $\alpha$-derived OMVs (Huang et al. 2016). The obtained Omp22-OMVs can effectively induce the generation of 0mp22-specific antibodies and Omp22-OMV immunization that could protect mice from assault originated from a clinically isolated $A$. baumannii strain, reduce bacterial burdens in many organs, suppress serum levels of inflammatory cytokines, and finally increase the therapeutic effect. These results strongly suggested that OMVs can protect the activity of the heterologous protein, which will ultimately lead to achieve controllable induction of specific antibody response for homologous bacterial infection.

Gao et al. (2015) reported a kind of bacterial outer membrane-coated AuNPs (BM-AuNPs) that preserved the biological characteristics of bacteria and could serve as a natural antigen to the immune system (Fig. 6A). For mice inoculated with BM-AuNPs, the dendritic cells in lymph nodes will be induced and maturated rapidly, and the consequent antibody responses are durable and more avid than those elicited by OMVs only. The production of IFN- $\gamma$ and IL-17 was also increased, demonstrating that the strong TH1- and TH17-based cell responses to pathogenic bacteria can be triggered by BM-AuNPs. This study shows that the reasonable combination of OMVs and nanomaterials will give full play to the advantages of both and promote the application of the complex in vaccine design.

Compared with the OMVs secreted from Gramnegative, the OMVs generated from Gram-positive bacteria are naturally free of LPS and theoretically have better safety. Thus, they are more valuable to become the carrier of vaccine delivery. Yuan et al. (2018) constructed a $S$. aureus membrane vesicle delivery system $\left({ }^{\Delta \mathrm{agr}} \mathrm{MVs}\right)$ from an agr locus deletion mutant of the $S$. aureus strain (RN4220- $\Delta$ agr) (Fig. 6B). The virulence of the membrane vesicles generated by the agr system of $S$. aureus which had been knocked was greatly reduced. And at least four high-abundance proteins, Mntc-FLAG, PdhB-FLAG, PdhA-FLAG, and Eno-FLAG, with the ability to carry foreign antigen molecules were identified from the bases of the membrane vesicles. Using the specific antigens of four serotypes of dengue virus as the model, 
A

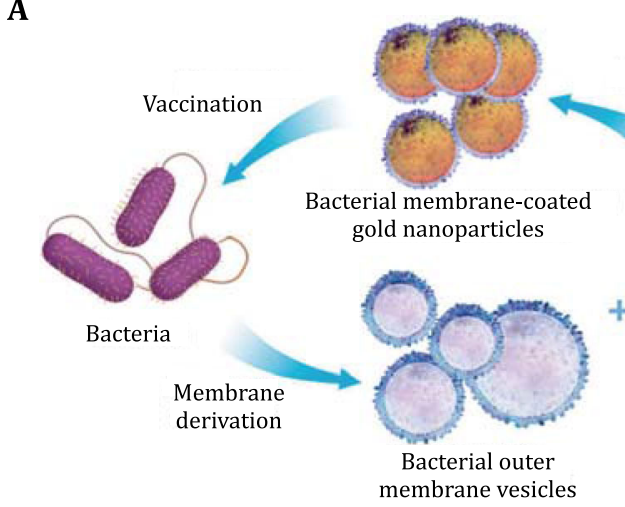

C a
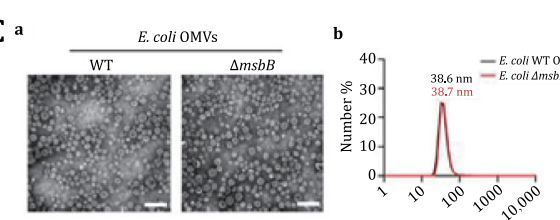

Membrane

coating

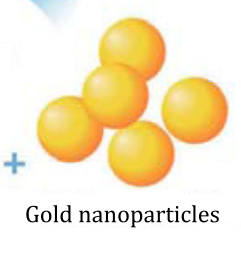

B

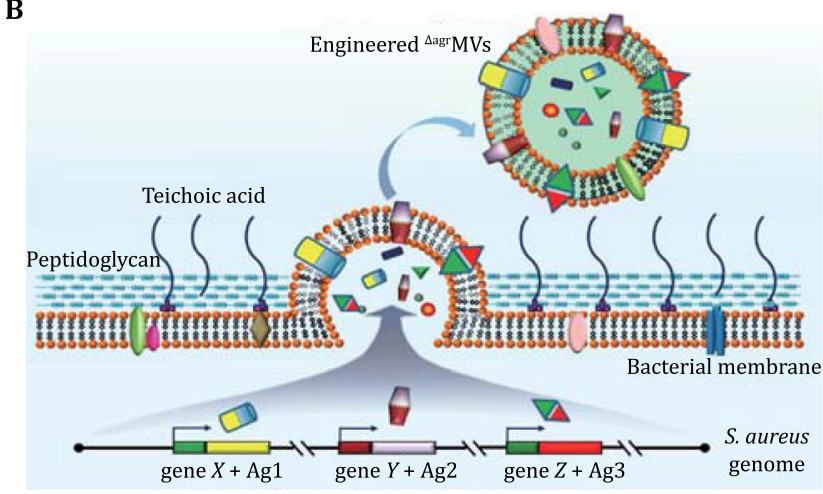

D
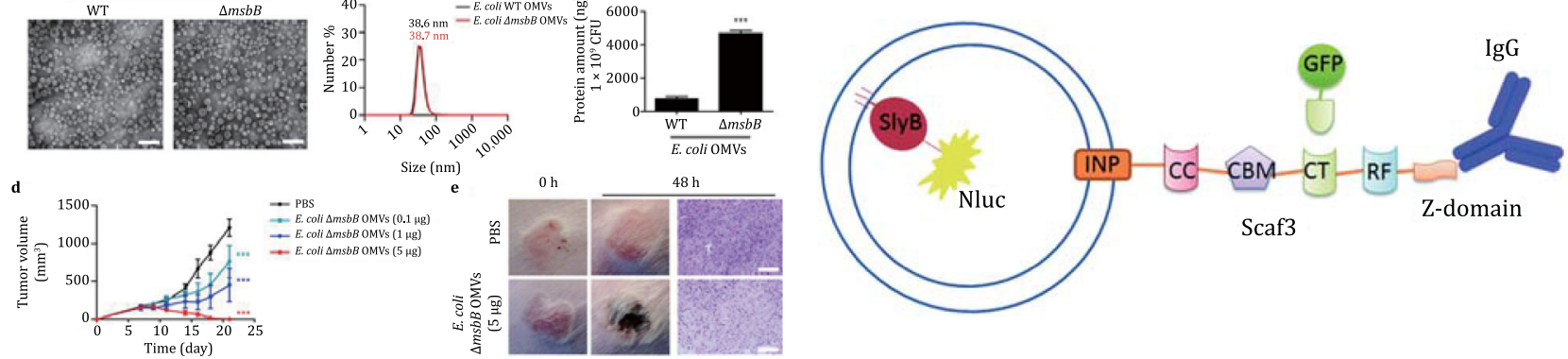

Fig. 6 Application of genetic modified OMV. A An unique bacterial membrane-coated nanoparticle system as a new and exciting antibacterial vaccine (Gao et al. 2015). B A safe multivalent nanoscale staphylococcal platform ( $\left.{ }^{\Delta a g r} \mathrm{MVs}\right)$ developed from the Staphylococcus aureus strain (RN4220- $\Delta$ agr). The ${ }^{\Delta \text { agr }}$ MV was authenticated as a capable tool for delivering heterologous viral antigens and against viral infections (Yuan et al. 2018). C OMVs derived from $\Delta m s b B$ mutant $E$. coli that bacterial endotoxin like LPS had been inactivated could be employed as therapeutic agents to treat cancer via immunotherapy (Kim et al. 2017a, b). D Engineering multifunctional OMV as modular nanodevice for biosensing and bioimaging (Chen et al. 2017)

the protective antigens (EDIIIconA/B) of two kinds of dengue virus were recombined to the coding genes of the principal components of the membrane vesicle by genetic engineering technology. And the polyvalent dengue membrane vesicle vaccine was developed and prepared by the membrane vesicle secretion mechanism of $S$. aureus. The preliminary evaluation of immunological efficacy shows that the prepared vaccines can induce the body to produce protective neutralizing antibody, which had a good ability against all the four serotypes virus of dengue.

Through genetic modification, OMVs can be endowed with the ability to deliver proteins and stimulate the body to generate immune protection. And more functions of OMVs will be discovered after further detailed study. Some studies have shown that OMVs from Gram-negative bacteria tend to inhibit the growth of hostile bacteria, which will protect their own parent bacterium. However, limited by the unclear mechanism and the general bactericidal ability, this interesting phenomenon has not been studied thoroughly. Perhaps through the genetic engineering, OMVs can obtain amplified and controlled bactericidal ability, and the relative mechanism will be understood eventually in the future (Li et al. 1998; Schulz et al. 2018).

\section{Genetically engineered OMVs for cancer treatment}

Cancer is the leading cause of the death in our society. There are probably 18.1 million new cancer cases and 9.6 million cancer deaths worldwide in 2018 (Bray et al. 2018). No time to lose in the fight against cancer (Motevalli et al. 2019; Sun et al. 2018). Previous lines of research have reported that bacteria such as Bifidobacterium bifidum and E. coli have ability to target tumor, proliferate in specific tumor cells, and trigger effective antitumor through specific immune factormediated immune response (Kim et al. 2015a, b; Pawelek et al. 2003). The OMVs derived from the abovementioned bacteria have many similar components like their parent bacterium, which may endow them same abilities for cancer treatment.

Kim et al. reported that the $\triangle m s b B$ OMVs obtained from the lipid A acyltransferase ( $m s b B$ )-deficient $E$. coli can be used as cancer immunotherapeutic agents and be successfully accumulated in tumor tissue via enhanced 
permeability and retention (Kim et al. 2017a, b). Provoked by trypsin-sensitive surface proteins of OMVs, the body could produce interferon (IFN) $\gamma$ in the tumor microenvironment, which would activate antitumor responses and inhibit the tumor growth. Compared with OMVs purified from wild-type E. coli, the $\triangle m s b B$ OMVs are considered safe (Fig. 6C). What needs to be pointed out is that the E. coli $\Delta \mathrm{msbB}$ had no direct antitumor effect and can lead to adverse reactions under certain circumstances.

Through a sorting mechanism, the various heterologous proteins can be carried by OMVs and their activities can also be retained. Thus, OMVs are advantageous for delivering the proteins and small-interfering RNA (siRNA) that are destructive to tumors. In the study of Vipul Gujrati et al.'s, the ClyA, an outer membraneenriched virulence factor, with high affinity to human epidermal growth factor receptor 2 (HER2)-targeting protein was genetically fused with an antibody and finally anchored on the OMV surface (Gujrati et al. 2014). The prepared $\mathrm{Affi}_{\mathrm{HER} 2} \mathrm{OMVs}$ with low immunogenicity were used to deliver siRNA that can target kinesin spindle protein and kill cancer cells in mice. Different from positive target like enhanced permeability and retention of OMVs as described above, in this work, OMVs were first given the ability to actively target tumors through the genetic engineering, which will effectively broaden the applicable scope of OMVs (Kaparakis-Liaskos and Ferrero 2015). In addition, OMVs will express a cancer-specific targeting ligand to deliver their payload like siRNA in a cell-selective manner after the modification of genetic engineering.

OMVs containing the bacteriotoxin like LPS possess the ability to provoke uncontrolled adverse responses like inflammation in the body, which limit their application in cancer treatment (Bonnington and Kuehn 2014). The OMVs obtained after special modification by genetic engineering do not show the original antigen toxicity any more, which provides the possibility for safe delivery of therapeutic agents in vivo. At the same time, the engineered OMVs not only can maintain the protein activity but also possess enhanced target ability and therapeutic effect for cancer treatment.

\section{Genetically engineered OMVs for bioimaging and detection}

Anchoring fusion proteins with special functions on bacterial outer membrane vesicles can achieve multiple purposes such as targeted protein transport, fluorescent molecular labeling, and tumor treatment. It can be achieved by anchoring the fusion proteins on the OMV membranes-associated protein through genetic modification. With the help from these membrane proteins, fusion proteins were successfully fixed to the OMVs for vaccine preparation, enzyme assembly, siRNA silencing, cellular target, and living cell imaging as demonstrated in other synthetic systems (Park et al. 2014).

It is reported that antibody-decorated OMVs by genetic engineering can target the HER2, a receptor protein overexpressed in many malignant tumors (Baselga and Swain 2009). After loading TAMRA-labeled kinesin spindle protein (KSP) siRNA, the resultant $\mathrm{Affi}_{\mathrm{HER} 2} \mathrm{OMV}^{\text {siRNA-TAMRA }}$ can effectively inhibit tumor growth by KSP silencing and track the siRNA-Loaded Affi $_{\mathrm{HER} 2} \mathrm{OMVs}$ in vitro and in vivo (Gujrati et al. 2014). Since there is no direct fluorescence labeling of the OMVs, more information about the activity of OMVs cannot be known in vivo. The proteins modified on OMVs often have a single function and the role of other anchors on OMVs cannot be effectively utilized, which would limit the application of the modified OMVs. Thus, the abilities about OMVs decorated with multiple functional protein moieties need to be further studied.

The E. coli has the natural ability to classify proteins as interior and exterior of OMVs, which makes the proteins in the interior and exterior membrane have obvious specificity. Through simultaneous decorations of both interior and exterior membranes with functional capturing and reporting moieties assisted by gene engineering, Chen et al. (2017) developed one kind of dual-functionalized OMVs as a modular platform for intracellular imaging (Fig. 6D). The SlyB, existed to the side of periplasm of the outer membrane of $E$. coli, was immobilized to the interior of OMVs for anchoring target fluorescin (Plesa et al. 2006). In order to realize multitargeting, anchors like ice nucleation protein on the exterior of the OMVs were used to exhibit an antibodybinding $\mathrm{Z}$ domain for antibody binding simultaneously (Shimazu et al. 2003). To further modify the existing system with corresponding dockerin-tagged GFP for OMV imaging, the Scaf3 that contains three orthogonal cohesin domains was inserted between the ice nucleation protein and $\mathrm{Z}$ domain (Tsai et al. 2009). The detectable concentration of thrombin was as low as $0.5 \mathrm{nmol} / \mathrm{L}$ through this OMVs, which indicated that the multi-functionalized OMVs had a powerful ability for biosensing and bioimaging.

Not much attention has been paid to the biosensing and bioimaging using the engineered OMV at present. However, to benefit from the easily customized by genetic modifications, many OMVs with special capabilities will be assembled for a broad of applications including live imaging. 


\section{SUMMARY AND PERSPECTIVE}

OMV secreted throughout the life of all Gram-negative and Gram-positive bacteria that have been investigated is essential for bacteria to maintain their normal physiological activities. OMV is a spherical nanostructure with a size of $20-250 \mathrm{~nm}$ and consists of almost same components of the parent bacterium, and can be used as a tool for bacteria to resist the external pressure. OMV has many functions such as bacterial intercellular communication, DNA transfer, transportation of virulence factors, and interception of bacteriophages. Although many studies have reported the biogenesis of OMV, the process of formation needs more attention. Ultracentrifugation and precipitation are two major methods for the preparation of OMVs. The OMVs with regular morphology and uniform size can be obtained by ultracentrifugation, which is the most common method for the preparation of OMVs. However, the process is very complex. Although the OMVs can be prepared by precipitation method through a simple process, the salt solution with unsuitable saturation can destroy the protein on the surface of vesicles easily, so it is rarely used. The density gradient centrifugation and gel filtration can usually be used to purify the prepared vesicles.

OMV is a kind of natural immune adjuvants, which play an important role in vaccine preparation, infection prevention and control, tumor treatment, drug transportation, and biological imaging. However, under the influence of surface bacteriotoxin such as LPS and LTA, excessive immune response and subsequent inflammation are often induced during the application process. To solve these problems, chemical or genetic engineering techniques are often used to remove or passivate the bacteriotoxin on the surface of OMV. Chemical method is easy to inactivate or degrade proteins on the membrane surface while gene engineering technology is controllable, safe, and targeted, so more commonly used in practice. In recent years, genetically modified OMVs have been widely used in the biomedical field. And the OMVbased vaccine like Bexsero has been approved by the FDA for clinical treatment of meningitis. Through the proper use of protein sites on the surface of bacteria, target antigens, proteins, or other substances can be expressed on the surface of OMV, and the safer and more effective vaccine can be developed. When induced by OMV, IFN- $\gamma$ can be produced from the immune system and finally kill the cancer cell. At the same time, IFN- $\gamma$ and IL-17 can be produced through immune system under the stimulation of OMVs, which will then induce the Th1- and Th17based cell response to achieve the effective killing of homologous bacteria in vivo.
Great progress has been made in related areas since the discovery of OMV. However, there are still some problems needed to be addressed: (1) the existing biogenesis cannot fully explain the formation process of all bacterial vesicles, so further studies are needed; (2) the separation and purification processes of OMV are complex, which will restrict the development of relative research; (3) OMV is rarely used in other biomedical fields except research and development of vaccines; (4) how to balance the surface antigen activity and toxicity effectively need further research. To overcome these obstacles, more dynamic monitoring strategies like fluorescence imaging or in situ electron microscopy should be applied for understanding the biogenesis of OMV. Developing functional molecules, proteins, or enzymes that possess the ability to inhibit the activity of bacterial toxins on the OMVs' surface may be an effective strategy to reduce the immunogenicity of OMVs. And inspired by the strategies such as immunoaffinity capture, exosome precipitation, size-based and microfluidics-based isolation techniques that have been successfully applied to extract exosome from cells, similar extractive methods based on the characteristics of OMV can be developed (Li et al. 2017). There are reasons to believe that with the solution of the existing problems and the further studies, OMV-based nanotechnology will be evolved into a powerful toolkit for vaccine development, disease diagnosis, cancer therapy, and other related fields.

Acknowledgement This work was supported by the National Natural Science Foundation of China (81871733, 81601845, 31630027, and 81601603) and NSFC-DFG project (31761133013). The authors also appreciate the support by the Natural Science Foundation of Chongqing (CSTC2018JSCXMSYB1033) and the supports from Program for Innovation Team Building at Institutions of Higher Education in Chongqing (CXTDX201601046).

\section{Compliance with Ethical Standards}

Conflict of interest Guangchao Qing, Ningqiang Gong, Xiaohui Chen, Jing Chen, Hong Zhang, Yongchao Wang, Ruifang Wang, Shouwen Zhang, Zhen Zhang, Xianxian Zhao, Yang Luo, and XingJie Liang declare that they have no conflict of interest.

Human and animal rights and informed consent This article does not contain any studies with human or animal subjects performed by any of the authors.

Open Access This article is distributed under the terms of the Creative Commons Attribution 4.0 International License (http:// creativecommons.org/licenses/by/4.0/), which permits unrestricted use, distribution, and reproduction in any medium, provided you give appropriate credit to the original author(s) and the source, provide a link to the Creative Commons license, and indicate if changes were made. 


\section{References}

Apostolico Jde S, Lunardelli VA, Coirada FC, Boscardin SB, Rosa DS (2016) Adjuvants: classification, modus operandi, and licensing. J Immunol Res 2016:1459394

Baselga J, Swain SM (2009) Novel anticancer targets: revisiting ERBB2 and discovering ERBB3. Nat Rev Cancer 9(7):463-475

Bauman SJ, Kuehn MJ (2006) Purification of outer membrane vesicles from Pseudomonas aeruginosa and their activation of an IL-8 response. Microbes Infect 8(9-10):2400-2408

Baumgarten T, Sperling S, Seifert J, von Bergen M, Steiniger F, Wick LY, Heipieper HJ (2012) Membrane vesicle formation as a multiple-stress response mechanism enhances Pseudomonas putida DOT-T1E cell surface hydrophobicity and biofilm formation. Appl Environ Microbiol 78(17):6217-6224

Bishop D, Work E (1965) An extracellular glycolipid produced by Escherichia coli grown under lysine-limiting conditions. Biochem J 96(2):567-576

Bitto NJ, Kaparakis-Liaskos M (2017) The therapeutic benefit of bacterial membrane vesicles. Int J Mol Sci 18(6):1287

Bjune G, Hoiby E, Gronnesby J, Arnesen O, Fredriksen JH, Lindbak A, Nokleby H, Rosenqvist E, Solberg L, Closs $O$ (1991) Effect of outer membrane vesicle vaccine against group B meningococcal disease in Norway. The Lancet 338(8775):1093-1096

Bonnington KE, Kuehn MJ (2014) Protein selection and export via outer membrane vesicles. BBA-Mol Cell Res 1843(8):1612-1619

Bray F, Ferlay J, Soerjomataram I, Siegel RL, Torre LA, Jemal A (2018) Global cancer statistics 2018: GLOBOCAN estimates of incidence and mortality worldwide for 36 cancers in 185 countries. CA-Cancer J Clin 68(6):394-424

Brown L, Wolf JM, Prados-Rosales R, Casadevall A (2015) Through the wall: extracellular vesicles in Gram-positive bacteria, mycobacteria and fungi. Nat Rev Microbiol 13(10):620-630

Chatterjee D, Chaudhuri K (2013) Vibrio cholerae 0395 outer membrane vesicles modulate intestinal epithelial cells in a NOD1 protein-dependent manner and induce dendritic cellmediated Th2/Th17 cell responses. J Biol Chem 288(6):4299-4309

Chen DJ, Osterrieder N, Metzger SM, Buckles E, Doody AM, DeLisa MP, Putnam D (2010) Delivery of foreign antigens by engineered outer membrane vesicle vaccines. Proc Natl Acad Sci USA 107(7):3099-3104

Chen L, Valentine JL, Huang CJ, Endicott CE, Moeller TD, Rasmussen JA, Fletcher JR, Boll JM, Rosenthal JA, Dobruchowska J, Wang Z, Heiss C, Azadi P, Putnam D, Trent MS, Jones BD, DeLisa MP (2016) Outer membrane vesicles displaying engineered glycotopes elicit protective antibodies. Proc Natl Acad Sci USA 113(26):E3609-E3618

Chen Q, Rozovsky S, Chen W (2017) Engineering multi-functional bacterial outer membrane vesicles as modular nanodevices for biosensing and bioimaging. Chem Commun 53(54):7569-7572

Chin W-C, Kim JH, Yoon YJ, Lee J, Choi E-J, Yi N, Park K-S, Park J, Lötvall J, Kim Y-K, Gho YS (2013) Outer membrane vesicles derived from Escherichia coli up-regulate expression of endothelial cell adhesion molecules in vitro and in vivo. PLoS One 8(3):e59276

Choi SJ, Kim MH, Jeon J, Kim OY, Choi Y, Seo J, Hong SW, Lee WH, Jeon SG, Gho YS, Jee YK, Kim YK (2015) Active immunization with extracellular vesicles derived from Staphylococcus aureus effectively protects against staphylococcal lung infections, mainly via Th1 cell-mediated immunity. PLoS One 10(9):e0136021
Dorward DW, Garon CF (1990) DNA is packaged within membrane-derived vesicles of Gram-negative but not Grampositive bacteria. Appl Environ Microbiol 56(6):1960-1962

Ellis TN, Kuehn MJ (2010) Virulence and immunomodulatory roles of bacterial outer membrane vesicles. Microbiol Mol Biol Rev 74(1):81-94

Fantappie L, de Santis M, Chiarot E, Carboni F, Bensi G, Jousson O, Margarit I, Grandi G (2014) Antibody-mediated immunity induced by engineered Escherichia coli OMVs carrying heterologous antigens in their lumen. J Extracell Vesicles 3:24015. https://doi.org/10.3402/jev.v3.24015

Gao W, Fang RH, Thamphiwatana S, Luk BT, Li J, Angsantikul P, Zhang $\mathrm{Q}, \mathrm{Hu} \mathrm{CM}$, Zhang L (2015) Modulating antibacterial immunity via bacterial membrane-coated nanoparticles. Nano Lett 15(2):1403-1409

Gnopo YMD, Watkins HC, Stevenson TC, DeLisa MP, Putnam D (2017) Designer outer membrane vesicles as immunomodulatory systems-reprogramming bacteria for vaccine delivery. Adv Drug Deliv Rev 114:132-142

Guidi R, Levi L, Rouf SF, Puiac S, Rhen M, Frisan T (2013) Salmonella enterica delivers its genotoxin through outer membrane vesicles secreted from infected cells. Cell Microbiol 15(12):2034-2050

Gujrati V, Kim S, Kim S-H, Min JJ, Choy HE, Kim SC, Jon S (2014) Bioengineered bacterial outer membrane vesicles as cellspecific drug-delivery vehicles for cancer therapy. ACS Nano 8(2):1525-1537

Haurat MF, Elhenawy W, Feldman MF (2015) Prokaryotic membrane vesicles: new insights on biogenesis and biological roles. Biol Chem 396(2):95-109

Huang W, Yao Y, Long Q, Yang X, Sun W, Liu C, Jin X, Li Y, Chu X, Chen B, Ma Y (2014) Immunization against multidrugresistant Acinetobacter baumannii effectively protects mice in both pneumonia and sepsis models. PLoS One 9(6):e100727

Huang W, Wang S, Yao Y, Xia Y, Yang X, Li K, Sun P, Liu C, Sun W, Bai H, Chu X, Li Y, Ma Y (2016) Employing Escherichia coliderived outer membrane vesicles as an antigen delivery platform elicits protective immunity against Acinetobacter baumannii infection. Sci Rep 6:37242

Jang SC, Kim SR, Yoon YJ, Park KS, Kim JH, Lee J, Kim OY, Choi EJ, Kim DK, Choi DS, Kim YK, Park J, Di Vizio D, Gho YS (2015) In vivo kinetic biodistribution of nano-sized outer membrane vesicles derived from bacteria. Small 11(4):456-461

Kaparakis-Liaskos M, Ferrero RL (2015) Immune modulation by bacterial outer membrane vesicles. Nat Rev Immunol 15(6):375-387

Kataoka M, Yamaoka A, Kawasaki K, Shigeri Y, Watanabe K (2014) Extraordinary denaturant tolerance of keratinolytic protease complex assemblies produced by Meiothermus ruber $\mathrm{H} 328$. Appl Microbiol Biotechnol 98(7):2973-2980

Kim JE, Phan TX, Nguyen VH, Dinh-Vu HV, Zheng JH, Yun M, Park SG, Hong Y, Choy HE, Szardenings M, Hwang W, Park JA, Park S, Im SH, Min JJ (2015a) Salmonella typhimurium suppresses tumor growth via the pro-inflammatory cytokine interleukin1beta. Theranostics 5(12):1328-1342

Kim JH, Lee J, Park J, Gho YS (2015b) Gram-negative and Grampositive bacterial extracellular vesicles. Semin Cell Dev Biol 40:97-104

Kim OY, Dinh NT, Park HT, Choi SJ, Hong K, Gho YS (2017a) Bacterial protoplast-derived nanovesicles for tumor targeted delivery of chemotherapeutics. Biomaterials 113:68-79

Kim OY, Hong BS, Park KS, Yoon YJ, Choi SJ, Lee WH, Roh TY, Lotvall J, Kim YK, Gho YS (2013) Immunization with Escherichia coli outer membrane vesicles protects 
bacteria-induced lethality via Th1 and Th17 cell responses. J Immunol 190(8):4092-4102

Kim OY, Park HT, Dinh NTH, Choi SJ, Lee J, Kim JH, Lee S-W, Gho YS (2017b) Bacterial outer membrane vesicles suppress tumor by interferon- $\gamma$-mediated antitumor response. Nat Commun $8(1): 626$

Klimentova J, Stulik J (2015) Methods of isolation and purification of outer membrane vesicles from gram-negative bacteria. Microbiol Res 170:1-9

Knox K, Vesk M, Work E (1966) Relation between excreted lipopolysaccharide complexes and surface structures of a lysine-limited culture of Escherichia coli. J Bacteriol 92(4):1206-1217

Kuehn MJ (2012) Secreted bacterial vesicles as good samaritans. Cell Host Microbe 12(4):392-393

Kuipers K, Daleke-Schermerhorn MH, Jong WS, ten HagenJongman CM, van Opzeeland F, Simonetti E, Luirink J, de Jonge MI (2015) Salmonella outer membrane vesicles displaying high densities of pneumococcal antigen at the surface offer protection against colonization. Vaccine 33(17):2022-2029

Kulkarni HM, Jagannadham MV (2014) Biogenesis and multifaceted roles of outer membrane vesicles from Gram-negative bacteria. Microbiology 160(Pt 10):2109-2121

Kulkarni HM, Swamy CVB, Jagannadham MV (2014) Molecular characterization and functional analysis of outer membrane vesicles from the antarctic bacterium Pseudomonas syringae suggest a possible response to environmental conditions. J Proteome Res 13(3):1345-1358

Kulp A, Kuehn MJ (2010) Biological functions and biogenesis of secreted bacterial outer membrane vesicles. Annu Rev Microbiol 64:163-184

Lee EY, Choi DY, Kim DK, Kim JW, Park JO, Kim S, Kim SH, Desiderio DM, Kim YK, Kim KP, Gho YS (2009) Gram-positive bacteria produce membrane vesicles: proteomics-based characterization of Staphylococcus aureus-derived membrane vesicles. Proteomics 9(24):5425-5436

Li P, Kaslan M, Lee SH, Yao J, Gao Z (2017) Progress in exosome isolation techniques. Theranostics 7(3):789-804

Li ZS, Clarke AJ, Beveridge TJ (1998) Gram-negative bacteria produce membrane vesicles which are capable of killing other bacteria. J Bacteriol 180(20):5478-5483

Li ZT, Zhang RL, Bi XG, Xu L, Fan M, Xie D, Xian Y, Wang Y, Li XJ, Wu ZD, Zhang KX (2015) Outer membrane vesicles isolated from two clinical Acinetobacter baumannii strains exhibit different toxicity and proteome characteristics. Microb Pathog 81:46-52

MacDonald IA, Kuehn MJ (2013) Stress-induced outer membrane vesicle production by Pseudomonas aeruginosa. J Bacteriol 195(13):2971-2981

Manning AJ, Kuehn MJ (2011) Contribution of bacterial outer membrane vesicles to innate bacterial defense. BMC Microbiol 11:258

Mashburn LM, Whiteley M (2005) Membrane vesicles traffic signals and facilitate group activities in a prokaryote. Nature 437(7057):422-425

McCaig WD, Koller A, Thanassi DG (2013) Production of outer membrane vesicles and outer membrane tubes by Francisella novicida. J Bacteriol 195(6):1120-1132

Motevalli SM, Eltahan AS, Liu L, Magrini A, Rosato N, Guo W, Bottini M, Liang X-J (2019) Co-encapsulation of curcumin and doxorubicin in albumin nanoparticles blocks the adaptive treatment tolerance of cancer cells. Biophys Rep 5(1):19-30

Needham BD, Trent MS (2013) Fortifying the barrier: the impact of lipid A remodelling on bacterial pathogenesis. Nat Rev Microbiol 11(7):467-481
Needham BD, Carroll SM, Giles DK, Georgiou G, Whiteley M, Trent MS (2013) Modulating the innate immune response by combinatorial engineering of endotoxin. Proc Natl Acad Sci USA 110(4):1464-1469

Oishi S, Miyashita M, Kiso A, Kikuchi Y, Ueda O, Hirai K, Shibata Y, Fujimura S (2010) Cellular locations of proteinases and association with vesicles in Porphyromonas gingivalis. Eur J Med Res 15(9):397-402

Orench-Rivera N, Kuehn MJ (2016) Environmentally controlled bacterial vesicle-mediated export. Cell Microbiol 18(11):1525-1536

Park M, Sun Q Liu F, DeLisa MP, Chen W (2014) Positional assembly of enzymes on bacterial outer membrane vesicles for cascade reactions. PLoS One 9(5):e97103

Pathirana RD, Kaparakis-Liaskos M (2016) Bacterial membrane vesicles: biogenesis, immune regulation and pathogenesis. Cell Microbiol 18(11):1518-1524

Pawelek JM, Low KB, Bermudes D (2003) Bacteria as tumourtargeting vectors. Lancet Oncol 4(9):548-556

Petousis-Harris H, Paynter J, Morgan J, Saxton P, McArdle B, Goodyear-Smith F, Black S (2017) Effectiveness of a group B outer membrane vesicle meningococcal vaccine against gonorrhoea in New Zealand: a retrospective case-control study. The Lancet 390(10102):1603-1610

Plesa M, Hernalsteens JP, Vandenbussche G, Ruysschaert JM, Cornelis P (2006) The SlyB outer membrane lipoprotein of Burkholderia multivorans contributes to membrane integrity. Res Microbiol 157(6):582-592

Price NL, Goyette-Desjardins G, Nothaft H, Valguarnera E, Szymanski CM, Segura M, Feldman MF (2016) Glycoengineered outer membrane vesicles: a novel platform for bacterial vaccines. Sci Rep 6:24931

Rivera J, Cordero RJ, Nakouzi AS, Frases S, Nicola A, Casadevall A (2010) Bacillus anthracis produces membrane-derived vesicles containing biologically active toxins. Proc Natl Acad Sci USA 107(44):19002-19007

Roier S, Zingl FG, Cakar F, Durakovic S, Kohl P, Eichmann TO, Klug L, Gadermaier B, Weinzerl K, Prassl R, Lass A, Daum G, Reidl J, Feldman MF, Schild S (2016) A novel mechanism for the biogenesis of outer membrane vesicles in Gram-negative bacteria. Nat Commun 7:10515

Romeu B, Lastre M, Garcia L, Cedre B, Mandariote A, Farinas M, Oliva R, Rosenqvist E, Perez O (2014) Combined meningococcal serogroup A and W135 outer-membrane vesicles activate cell-mediated immunity and long-term memory responses against non-covalent capsular polysaccharide $\mathrm{A}$ Immunol Res 58(1):75-85

Ruiz N, Kahne D, Silhavy TJ (2006) Advances in understanding bacterial outer-membrane biogenesis. Nat Rev Microbiol 4(1):57-66

Schertzer JW, Whiteley M (2012) A bilayer-couple model of bacterial outer membrane vesicle biogenesis. MBio 3(2):e00297-11

Schulz E, Goes A, Garcia R, Panter F, Koch M, Muller R, Fuhrmann K, Fuhrmann G (2018) Biocompatible bacteria-derived vesicles show inherent antimicrobial activity. J Control Release 290:46-55

Schwechheimer C, Kuehn MJ (2013) Synthetic effect between envelope stress and lack of outer membrane vesicle production in Escherichia coli. J Bacteriol 195(18):4161-4173

Schwechheimer C, Kuehn MJ (2015) Outer-membrane vesicles from Gram-negative bacteria: biogenesis and functions. Nat Rev Microbiol 13(10):605-619

Sharpe SW, Kuehn MJ, Mason KM (2011) Elicitation of epithelial cell-derived immune effectors by outer membrane vesicles of 
nontypeable Haemophilus influenzae. Infect Immun 79(11):4361-4369

Shen Y, Giardino Torchia ML, Lawson GW, Karp CL, Ashwell JD, Mazmanian SK (2012) Outer membrane vesicles of a human commensal mediate immune regulation and disease protection. Cell Host Microbe 12(4):509-520

Shimazu M, Nguyen A, Mulchandani A, Chen W (2003) Cell surface display of organophosphorus hydrolase in Pseudomonasputida using an ice-nucleation protein anchor. Biotechnol Progr 19(5):1612-1614

Silhavy TJ, Kahne D, Walker S (2010) The bacterial cell envelope. Cold Spring Harb Perspect Biol 2(5):a000414

Sun Z, Fu Y-X, Peng H (2018) Targeting tumor cells with antibodies enhances anti-tumor immunity. Biophys Rep 4(5):243-253

Thoma J, Manioglu S, Kalbermatter D, Bosshart PD, Fotiadis D, Muller DJ (2018) Protein-enriched outer membrane vesicles as a native platform for outer membrane protein studies. Commun Biol 1:23

Toyofuku M, Carcamo-Oyarce G, Yamamoto T, Eisenstein F, Hsiao CC, Kurosawa M, Gademann K, Pilhofer M, Nomura N, Eberl L (2017) Prophage-triggered membrane vesicle formation through peptidoglycan damage in Bacillus subtilis. Nat Commun 8(1):481

Toyofuku M, Nomura N, Eberl L (2019) Types and origins of bacterial membrane vesicles. Nat Rev Microbiol 17(1):13-24

Tsai SL, Oh J, Singh S, Chen R, Chen W (2009) Functional assembly of minicellulosomes on the Saccharomyces cerevisiae cell surface for cellulose hydrolysis and ethanol production. Appl Environ Microbiol 75(19):6087-6093

Turnbull L, Toyofuku M, Hynen AL, Kurosawa M, Pessi G, Petty NK, Osvath SR, Carcamo-Oyarce G, Gloag ES, Shimoni R, Omasits U, Ito S, Yap X, Monahan LG, Cavaliere R, Ahrens CH, Charles IG, Nomura N, Eberl L, Whitchurch CB (2016) Explosive cell lysis as a mechanism for the biogenesis of bacterial membrane vesicles and biofilms. Nat Commun 7:11220

Valentine JL, Chen L, Perregaux EC, Weyant KB, Rosenthal JA, Heiss C, Azadi P, Fisher AC, Putnam D, Moe GR, Merritt JH, DeLisa MP (2016) Immunization with outer membrane vesicles displaying designer glycotopes yields class-switched, glycanspecific antibodies. Cell Chem Biol 23(6):655-665 van de Waterbeemd B, Streefland M, van der Ley P, Zomer B, van Dijken H, Martens D, Wijffels R, van der Pol L (2010) Improved OMV vaccine against Neisseria meningitidis using genetically engineered strains and a detergent-free purification process. Vaccine 28(30):4810-4816

van de Waterbeemd B, Zomer G, van den Ijssel J, van Keulen L, Eppink MH, van der Ley P, van der Pol LA (2013) Cysteine depletion causes oxidative stress and triggers outer membrane vesicle release by Neisseria meningitidis; implications for vaccine development. PLoS One 8(1):e54314

van der Pol L, Stork M, van der Ley P (2015) Outer membrane vesicles as platform vaccine technology. Biotechnol J 10(11):1689-1706

Vanaja SK, Russo AJ, Behl B, Banerjee I, Yankova M, Deshmukh SD, Rathinam VAK (2016) Bacterial outer membrane vesicles mediate cytosolic localization of LPS and caspase-11 activation. Cell 165(5):1106-1119

Vernikos G, Medini D (2014) Bexsero(R) chronicle. Pathog Glob Health 108(7):305-316

Watkins HC, Rappazzo CG, Higgins JS, Sun X, Brock N, Chau A, Misra A, Cannizzo JPB, King MR, Maines TR, Leifer CA, Whittaker GR, DeLisa MP, Putnam D (2017) Safe recombinant outer membrane vesicles that display M2e elicit heterologous influenza protection. Mol Ther 25(4):989-1002

Xue X, Zhao Y, Zhang X, Zhang C, Kumar A, Zhang X, Zou G, Wang PC, Zhang J, Liang XJ (2015) Phenylboronic acidfunctionalized magnetic nanoparticles for one-step saccharides enrichment and mass spectrometry analysis. Biophys Rep 1:61-70

Yuan J, Yang J, Hu Z, Yang Y, Shang W, Hu Q Zheng Y, Peng H, Zhang X, Cai X, Zhu J, Li M, Hu X, Zhou R, Rao X (2018) Safe staphylococcal platform for the development of multivalent nanoscale vesicles against viral infections. Nano Lett 18(2):725-733

Zariri A, Beskers J, van de Waterbeemd B, Hamstra HJ, Bindels TH, van Riet E, van Putten JP, van der Ley P (2016) Meningococcal outer membrane vesicle composition-dependent activation of the innate immune response. Infect Immun 84(10): 3024-3033 